\title{
Influence of vertical loads on lateral pile group response considering soil-pile-cap
}

\author{
interactions
}

\author{
Mahmoud N. Hussien*, Tetsuo Tobita**, and Susumu Iai*** \\ * PhD student Dept. of Civil and Earth Resources Eng. Kyoto University (Katsura Campus, Nishikyo-ku, Kyoto, 615-8540) \\ ** Member Dr. of Eng. Ass. Prof. Disaster Prevention Research Institute, Kyoto University (Gokasho, Uji, Kyoto, 611-0011) \\ *** Member Dr. of Eng. Prof. Disaster Prevention Research Institute, Kyoto University (Gokasho, Uji, Kyoto, 611-0011)
}

\begin{abstract}
This paper presents the results of a numerical investigation conducted to study the effect of vertical loads on lateral response of a free head and a capped pile group in sand. A coupled soil-pile system is idealized through 2D finite elements with soil models idealized by a hyperbolic type multiple shear mechanism. The analysis focuses on the five piles in the middle row of a $3 \times 5$ pile group spaced at 3.92-pile diameters. The interaction between a pile and the surrounding soil in the 3D type is idealized in the $2 \mathrm{D}$ analysis using soil-pile interaction springs with a hysteretic non-linear load displacement relationship. The presence of vertical loads on free head piles increases the confining pressures in the sand deposit confined by the piles but the rate of increase in those outside the group is relatively small, resulting in the difference in a balance of lateral soil pressures acting at the back of and in front of individual piles. A vertical load applied to a group pile with a uniform vertical displacement of 0.1 pile diameter decreases the lateral resistance of the leading pile (pile 1) by $10 \%$ and increases the lateral resistance of piles 3 and 5 by 14 and $35 \%$, respectively. The same trend with higher percentages of increase or decrease is observed in the capped pile group case.
\end{abstract}

Key Words: Pile group; lateral loads; vertical loads, confining pressure; soil-pile-cap interaction

\section{Introduction}

Pile groups connected by concrete caps are used in building and bridge structures to support a combination of both vertical and lateral loads which result from the weight of the structure and any acting sea wave or seismic forces. All methods of analysis consider that axial and lateral loads act independently, assuming that there is no interaction.

The results available in the literature ${ }^{1-3)}$ with respect to the effects of vertical loads on the lateral response of single pile suggested a significant increase in the lateral resistance of piles in the presence of vertical loads. Zhang et al. ${ }^{4)}$ through centrifuge experiments on $3 \times 3$ and $4 \times 4$ fixed-head battered pile groups concluded that the effects of vertical load on the lateral resistance of $3 \times 3$ pile groups were not significant. For $4 \times 4$ pile groups however, the lateral resistances increased significantly with vertical loads. Karthigeyan and Ramakrishna ${ }^{5}$ and Karthigeyan et al. ${ }^{6)}$, ) showed through a series of finite-element analyses on single piles that the presence of vertical loads increases the lateral load capacity of piles in sandy soils by as much as $40 \%$.
In fact, the scopes of these recent studies were limited to the behavior of single piles. Yet, little work has been devoted to the behavior of pile groups subject to the combined action of vertical and lateral loads. Moreover, the effect of the inclusion of pile caps on the interaction between vertical and lateral load was not fully examined.

The objective of this study was to help quantify the effect of vertical loads on the lateral resistance of pile groups not only for free head piles, but also for capped piles. A 2D finite element (FE) analysis based on a multi-shear mechanism constitutive relationship, FLIP ${ }^{8)}$ was used to this end. The second and third authors have been developing the constitutive equation based on the multi-shear mechanism and the computer code for FLIP as well as the application to static and dynamic performance of various geotechnical structures. The constitutive model used in FLIP has a potential capability to take into account the stress change induced in the soil due to vertical loads applied to piles prior to the application of lateral loads. In this model, directional shear stress contributions due to contact forces between sand particles are idealized by evenly distributed multiple springs, 


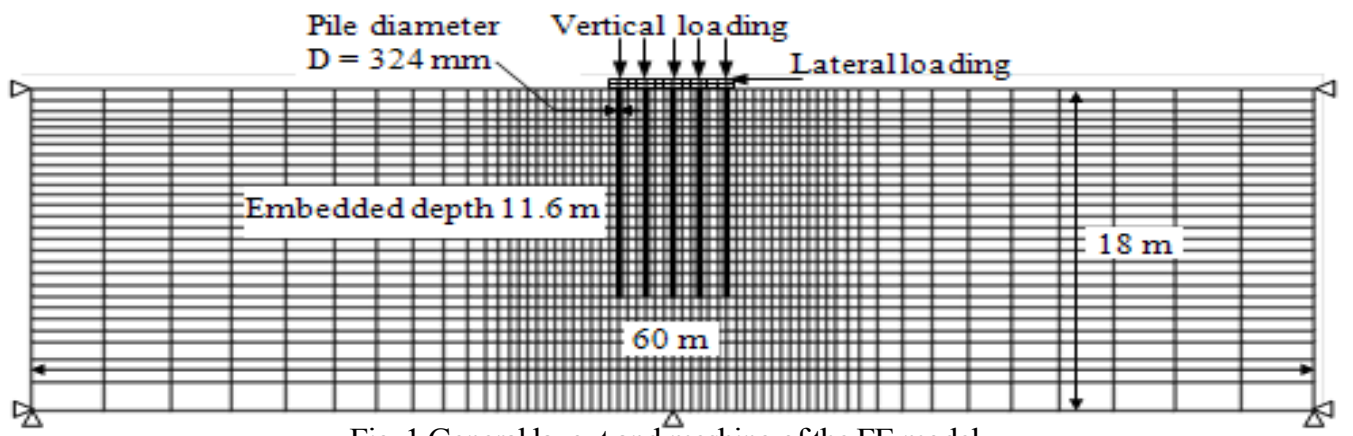

Fig. 1 General layout and meshing of the FE model.

whose property is characterized by a hyperbolic type. The model automatically accommodates the principal stress rotation, which has a significant effect on the strength and deformation behavior of granular soils. In addition, the applicability of the computer code FLIP to the analysis of pile groups under lateral loads has been confirmed through a study based on a full scale test of a 3 by 5 pile group at the Salt Lake City International Airport ${ }^{9)}$.

After the description of the finite element model used in this study, a brief review was given to the applicability of the model to the full scale test of a pile group. This paper then presented the initial part of the study that analyses the effect of vertical loads on the lateral resistance of a single pile with and without a pile cap, to be followed by the main part of the study with respect to the behavior of free head and capped pile groups. The primary findings from this study were summarized as conclusions.

\section{Finite Element Modeling}

The 2D FE program FLIP was employed to analyze the behavior of pile groups under pure lateral loads and a combination of vertical and lateral loads. The analysis focused on the five piles in the middle row of a $3 \times 5$ pile group spaced at 3.92-pile diameters (pile diameter $=324 \mathrm{~mm}$ ). Prior to the analysis of pile group behavior, analysis of single piles was performed as a reference in order to discuss the specific behavior of the pile group under combined loads. Two type of pile cap conditions were considered in the analysis: no cap condition, in which the top and bottom of the piles were set as displacement and rotation free, and capped pile conditions in which a concrete cap with $0.495 \mathrm{~m}$ thickness attached to the ground surface was considered. Figure 1 shows the general layout and meshing of the FE model with a concrete cap attached to the ground surface. The same meshing of the soil profile was used to analyze the single pile. Side boundary displacements were fixed in the horizontal direction, while those at the bottom boundary were fixed in both the horizontal and vertical directions.

A total of 8 cases were considered in the analysis. Pure lateral loads were considered in half of these cases while a combination of vertical and lateral loads were considered in the others. In the analysis, a vertical displacement (V) of $0.1 \mathrm{D}(\mathrm{D}=$ pile diameter) was applied at the pile head $(0.495 \mathrm{~m}$ above the ground surface ) prior to the application of lateral loads for both the single and grouped piles then lateral loads were statically applied at the same points until a target lateral displacement of $60 \mathrm{~mm}$ was achieved. The maximum vertical applied displacement at the pile head was kept constant during the application of the lateral displacement.

\subsection{Soil Model}

The soil model used in this study consists of a multiple shear mechanism with the effective stress and strain vectors in plane strain condition expressed as

$$
\begin{aligned}
& \left\{\sigma^{\prime}\right\}^{T}=\left\{\begin{array}{lll}
\sigma_{x}^{\prime} & \sigma_{y}^{\prime} & \tau_{x y}
\end{array}\right\} \\
& \{\varepsilon\}^{T}=\left\{\begin{array}{lll}
\varepsilon_{x} & \varepsilon_{y} & \gamma_{x y}
\end{array}\right\}
\end{aligned}
$$

then the basic form of the constitutive relation is given by

$$
\left\{d \sigma^{\prime}\right\}=[D]\left(\{d \varepsilon\}-\left\{d \varepsilon_{p}\right\}\right)
$$

in which the term $\left\{d \varepsilon_{p}\right\}$ represents the volumetric strain increment due to dilatancy and is given by

$$
\left\{d \varepsilon_{p}\right\}^{T}=\left\{d \varepsilon_{p} / 2 \quad d \varepsilon_{p} / 2 \quad 0\right\}
$$

The stiffness matrix is given by

$$
[D]=K\left\{n^{(0)}\right\}\left\{n^{(0)}\right\}^{T}+\sum_{i=1}^{I} G_{L / U}^{(i)}\left\{n^{(i)}\right\}\left\{n^{(i)}\right\}^{T}
$$

where the first term represents the volumetric mechanism with elastic tangent bulk modulus of soil skeleton $K$ and the direction vector given by 
$\left\{n^{(0)}\right\}^{T}=\left\{\begin{array}{lll}1 & 1 & 0\end{array}\right\}$

and the second term represents the multiple shear mechanism without volume change. Each mechanism $i=1, \ldots, I$ represents a virtual simple shear mechanism, with each simple shear plane oriented at an angle $\theta_{i} / 2+\pi / 4$ relative to the $x$ axis. The tangential shear modulus $G^{(i)}{ }_{L / U}$ represents the hyperbolic stress strain relationship with hysteresis characteristics. The direction vectors for the multiple shear mechanism are given by

$$
\begin{aligned}
& \left\{n^{(i)}\right\}^{T}=\left\{\begin{array}{lll}
\cos \theta_{i} & -\cos \theta_{i} & \sin \theta_{i}
\end{array}\right\}(\text { for } i=1, \ldots, I) \\
& \left.\theta_{i}=(i-1) \Delta \theta \quad \text { (for } i=1, \ldots \ldots, I\right) \\
& \Delta \theta=\pi / I \quad(\text { for } i=1, \ldots, I)
\end{aligned}
$$

The loading (L) and unloading (U) for shear mechanism are separately defined for each mechanism by the sign of $\left\{n^{(i)}\right\}^{T}\{d \varepsilon\}$. Each tangent modulus $G^{(i)}{ }_{L / U}$ depends on the present state and the history of each virtual simple shear strain $\gamma^{(i)}$. The virtual shear stress $q^{(i)}$ is introduced as the shear resistance variable to be defined per unit angle $\theta$ for mechanism $i$. When the inherent soil fabric is assumed to be isotropic, the virtual simple shear mechanism is defined by a hyperbolic relation under a constant confining stress as

$$
q^{(i)}=\frac{\gamma^{(i)} / \gamma_{v}}{1+\left|\gamma^{(i)} / \gamma_{v}\right|} q_{v}
$$

where $q_{v}$ and $\gamma_{v}$ are the parameters for defining the hyperbolic relationship and called the virtual shear strength and virtual reference strain, respectively. The virtual tangent shear moduli are obtained for the initial loading as

$$
G_{L / U}^{(i)}=\frac{\gamma^{(i)} / \gamma_{v}}{\left(1+\left|\gamma^{(i)} / \gamma_{v}\right|\right)^{2}} \frac{q_{v}}{\gamma_{v}} \Delta \theta
$$

The relationships between the parameters $q_{v}$ and $\gamma_{v}$ and the macroscopic shear strength $\tau_{m}$ and shear modulus $G_{m}$ can be written as

$$
\begin{aligned}
& G_{m}=\frac{q_{v}}{\gamma_{v}} \sum_{i=1}^{I} \sin ^{2} \theta_{i} \Delta \theta \\
& \tau_{m}=q_{v} \sum_{i=1}^{I} \sin ^{2} \theta_{i} \Delta \theta
\end{aligned}
$$

The shear modulus $G_{m}$ corresponding to effective mean stress $\sigma_{m}^{\prime}$ is related to the initial shear modulus $G_{m a}$ corresponding to initial effective mean stress $\sigma_{m a}^{\prime}$ as

$G_{m}=G_{m a}\left(\frac{\sigma_{m}^{\prime}}{\sigma_{m a}^{\prime}}\right)^{m G}$

The shear strength is related to the angle of internal friction $\phi_{f}$ and cohesion c as

$$
\tau_{m}=c \cos \phi_{f}+\sigma_{m}^{\prime} \sin \phi_{f}
$$

In the analysis, a uniform layer of sand was used. Model parameters of the sand layer are shown shaded in Table 1.

\subsection{Pile Model}

Bilinear one-dimensional beam elements with three degrees of freedom per node were used to model the piles. Normal force, shear force, and bending moment of each element were obtained directly from the finite element program. Table 2 defines the model parameters of pile elements. The parameters for piles were obtained from the industrial standard ${ }^{10)}$.

\subsection{Pile Cap Model}

Linear plan elements with two degrees of freedom per node were used to model the concrete pile caps. The Elastic modulus (E), Possion's ratio (v), and density $(\rho)$ were set to be $40 \mathrm{GPa}, 0.18$, and $2.5 \mathrm{t} / \mathrm{m}^{3}$, respectively.

\subsection{Soil-Structure Interface}


Joint elements were used at the soil-pile and soil-cap interfaces to represent sliding mechanism between them. Sliding will be initiated when the shear stress at the interface exceeds a certain value of $\tau_{f}$ given by the equation:

$$
\tau_{f}=c_{J}+\sigma \tan \phi_{J}
$$

where $c_{J}$ and $\phi_{J}$ are shear strength parameters of the soil at the interface. Model parameters for joints element are defined in Table 3.

\subsection{End Bearing Spring}

The axial soil reactions at pile tips were simulated using nonlinear spring elements ( $Q-z$ curve). The nonlinear spring at the pile tip can be represented according to Zhang et al. ${ }^{11)}$ as:

Table 1. Idealized soil layers at the Salt Lake City test site and model parameters for soil element

\begin{tabular}{cccccccc}
\hline Soil layer & $\begin{array}{c}\text { Depth } \\
(\mathrm{m})\end{array}$ & $\begin{array}{c}\gamma_{\mathrm{sat}} \\
\left(\mathrm{t} / \mathrm{m}^{3}\right)\end{array}$ & $\begin{array}{c}\mathrm{G}_{\mathrm{ma}} \\
(\mathrm{kPa})\end{array}$ & $\begin{array}{c}\mathrm{K}_{\mathrm{a}} \\
(\mathrm{kPa})\end{array}$ & $\begin{array}{c}\phi_{\mathrm{f}} \\
(\text { degrees })\end{array}$ & $\begin{array}{c}\mathrm{c} \\
(\mathrm{kPa})\end{array}$ \\
\hline Soft clay & $0-1.22$ & & 12,200 & 31,720 & 27 \\
Soft clay & $1.22-2.14$ & 1.92 & 18,000 & 46,800 & & 40 \\
Soft clay & $2.14-3.06$ & & 15,800 & 41,080 & & 35 \\
Sand & $3.06-4.80$ & 1.83 & 161,000 & 418,600 & 38 & \\
Soft clay & $4.80-5.33$ & & 34,100 & 0.33 & 88,660 & & 56.9 \\
Soft clay & $5.33-5.87$ & 1.92 & 15,000 & 39,000 & & 25 \\
Soft clay & $5.87-6.48$ & & 32,400 & 84,240 & & 54 \\
Sand & $6.48-11.6$ & & 127,000 & 330,200 & 33 & \\
Sand & $11.6-18.00$ & 1.83 & 40,600 & 105,560 & 31 & \\
\hline
\end{tabular}

Table 2. Model parameters for pile element

\begin{tabular}{ccccc}
\hline $\begin{array}{c}\text { Gs } \\
(\mathrm{kPa})\end{array}$ & $v$ & $\begin{array}{c}\rho \\
\left(\mathrm{t} / \mathrm{m}^{3}\right)\end{array}$ & $\begin{array}{c}\text { Initial flexural } \\
\text { rigidity } \\
(\mathrm{kPa})\end{array}$ & $\begin{array}{c}\text { Flexural rigidity } \\
\text { after yield } \\
(\mathrm{kPa})\end{array}$ \\
\hline $77,500,000$ & 0.29 & 7.9 & 108,670 & 65,200 \\
\hline
\end{tabular}

Table 3. Model parameters for joint element

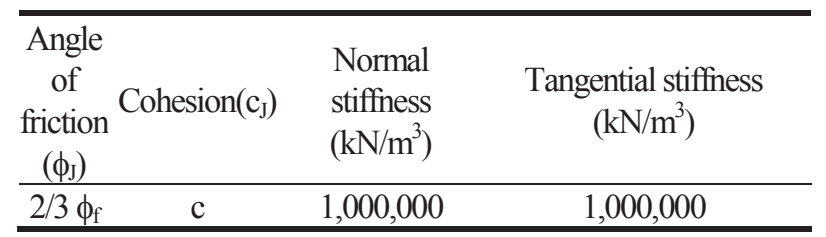

$$
z=\frac{Q_{b}(1-v)}{4 r_{o} G_{m a}\left(1-\frac{Q_{b}}{Q_{f}}\right)}
$$

where $Q_{f}$ is ultimate tip resistance (force). $G_{m a}$ and $v$ are initial shear modulus and Possion's ratio of the soil at the pile tip, respectively. $r_{o}$ is pile radius and $Q_{b}$ is mobilized tip resistance (force) for a given displacement $z$.

\subsection{Soil-pile Interaction Spring}

The interaction between a pile and the surrounding soil in 3D was idealized using a 2D analysis as follows. The nonlinear-spring element in Fig. 2 was used to represent the soil-pile interaction. The underlying concept of this spring was to analyze soil deformation between the piles in a row perpendicular to the direction of load. Parameters of the spring element were determined by parametric studies on the soil-pile interaction in a 2D horizontal plane as shown in Fig. 3. Figure 3(a) shows a single row of equally spaced piles deployed perpendicular to the direction of load, while Fig. 3(b) shows a simplified model for one pile in a group with boundaries parallel to the load direction that pass through the centers of the pile spacing. These boundaries were periodic and shared the same displacements at the boundary nodes with the same $\mathrm{x}$-coordinate where the $\mathrm{x}$-axis is towards the right. At the right and left side boundaries, displacements were fixed ${ }^{12}$.

Figure 4 shows the load-relative displacement relationship under cyclic loading where the relative displacement is defined as the difference in horizontal displacement between the center point of the pile and a point located at the boundary at $\mathrm{x}=0$. Figure 5 depicts the shear stress and shear strain relationship of a single soil element simulation under cyclic loading. The relationship between the load and relative displacement of a pile (Fig. 4) and the relationship between shear stress and shear strain of a single soil element (Fig. 5) were similar. Based on such similarities, the relationships between the relative displacement of a pile and the shear strain in an element test of the soil can be calibrated (more details can be found in Ozutsumi, et al 13)

\section{Applicability of the Finite Element Model to the Analysis of Pile Groups: A Review}

Before describing the results of the analyses of single piles and pile groups, a brief review was given to discuss the applicability of the analysis model used in this study to the behavior of pile groups under pure lateral loads. A full scale lateral load test of a $3 \times 5$ pile group was performed at the Salt Lake City Airport. The idealized soil layers at the test site and model parameters for soil elements used in the analysis are defined in Table 1. Soil properties were obtained from geotechnical investigation data at the site, including standard laboratory tests, unconsolidated-undrained (UU) traixial tests, consolidation tests, and in-situ tests such as cone penetration test, pressure meter test, and standard penetration test. 
For the full scale model tests, steel pipe piles were

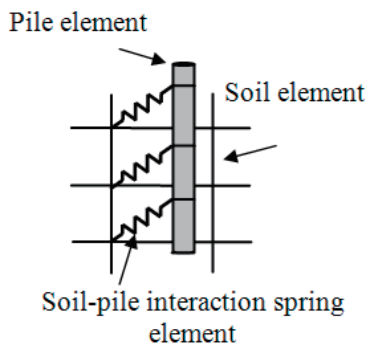

Fig. 2 Concept of the soil-pile interaction spring element.

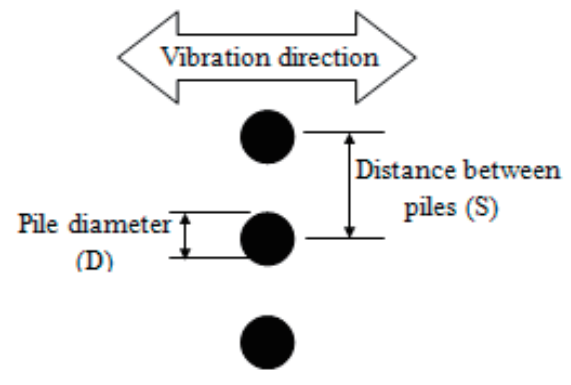

(a) Single row of equally spaced pile group.

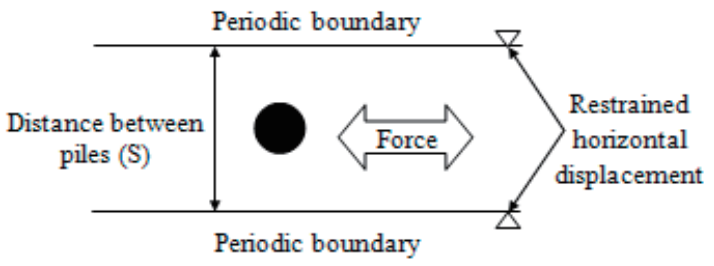

(b) Analysis domain for one pile in the group.

Fig. 32D analysis of the soil-pile system in a horizontal plane

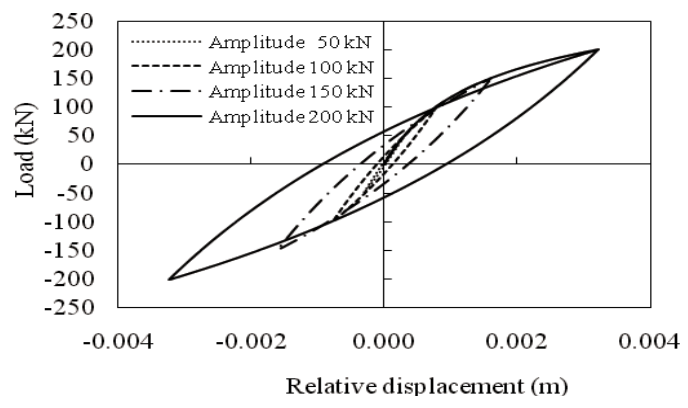

Fig. 4 The load-relative displacement relationship under cyclic loading.

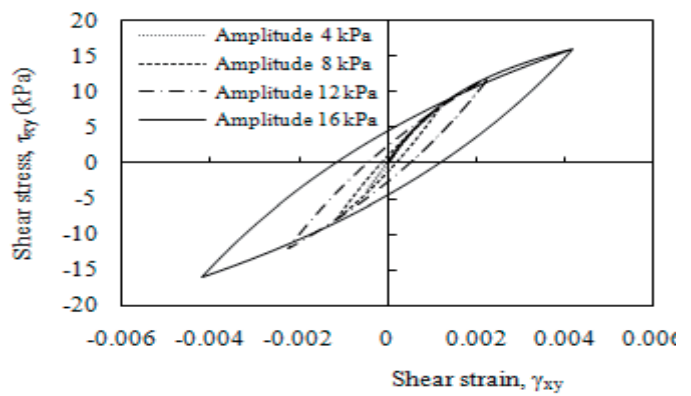

Fig. 5 Cyclic shear test simulation of a single soil element. driven closed end to an embedment depth of $11.6 \mathrm{~m}$. The test pile has a $0.324 \mathrm{~m}$ outside diameter with a 9.5 $\mathrm{mm}$ wall thickness. The piles in the group were driven in a $3 \times 5$ pattern with a nominal spacing of 3.92 pile diameters center to center in the loading direction and of 3.29 pile diameters perpendicular to the loading direction. The lateral load was applied $495 \mathrm{~mm}$ above the ground surface. The piles and the load frame are pin-connected so that the rotation is free at the pile head.

In the FE analysis of the full scale group pile test, lateral load was statically applied at piles heads $(0.495$ $\mathrm{m}$ above the ground surface) until the displacement of $90 \mathrm{~mm}$ at the loading point was achieved. Computed and measured average load per pile versus deflection for piles 1 (leading pile), 3 (middle pile), and 5 (trailing pile) are shown in Fig. 6. Both of the measured and the computed results indicate that the load distribution in the pile group is not uniform but is a function of the pile position. The computed results slightly overestimate the load carrying capacity of the leading pile while the computed loads of other piles are in good agreement
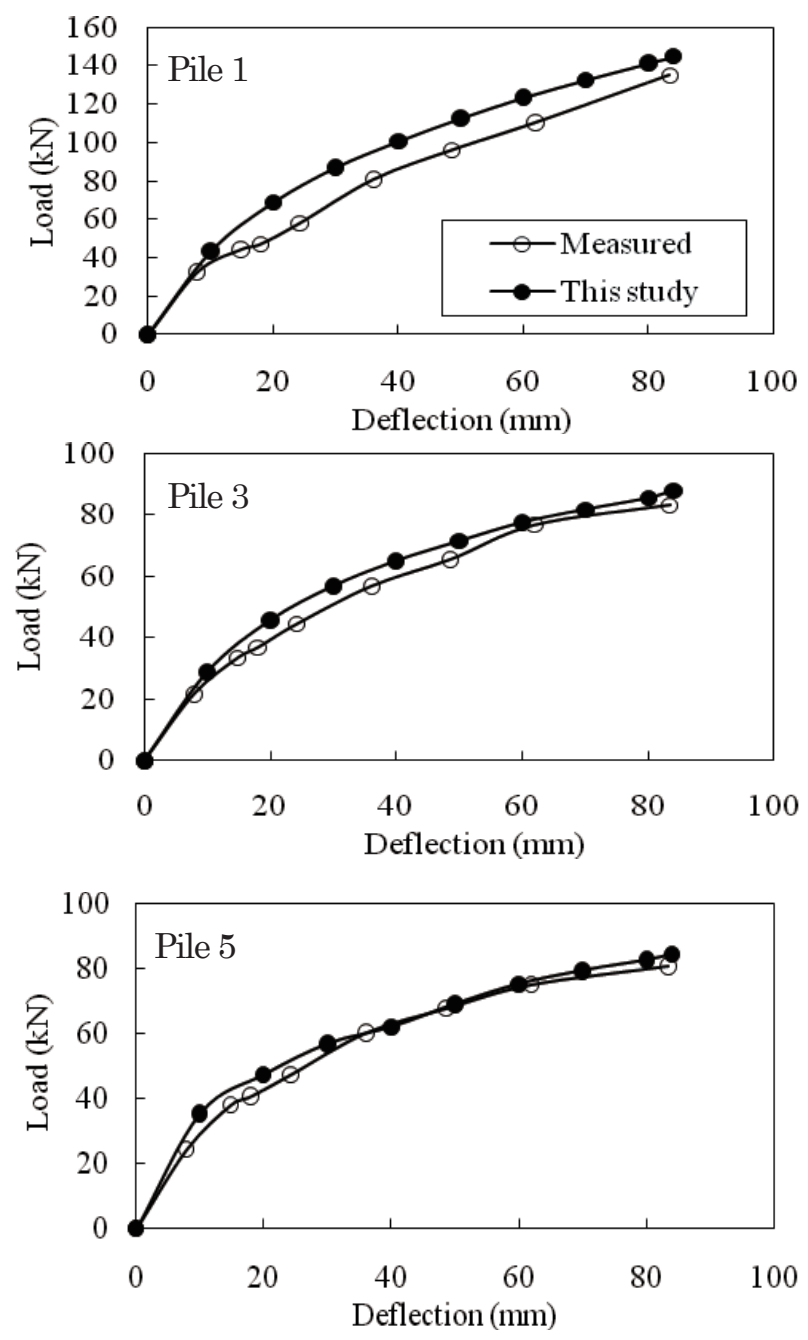

Fig. 6 Computed and measured average load per pile versus deflection for piles 1,3 , and 5 .

with the measured ones. The comparison can be considered as good for all practical design purposes. 
Consequently, the analysis model used for this study has a reasonable applicability to capture the essential behavior of pile group under pure lateral loads. More details on the analyses reviewed above could be found in Snyder ${ }^{9}$.

\section{Single Pile Response under the Combined Action of Vertical and Lateral Loads}

The soil profile and material parameters described in Section 2 were used for the analysis of single piles. Results of the analysis on free head and capped pile responses under both pure lateral and combined loads are shown in Fig. 7. Figure 7(a) indicates that a vertical load inducing a vertical displacement $(\mathrm{V}=0.1 \mathrm{D})$ of the pile head increases the lateral load-carrying capacity of a free head pile by $8 \%$ at a maximum lateral deflection of $60 \mathrm{~mm}$. A similar trend with a higher percentage of $19 \%$ at the maximum lateral deflection was observed in the capped pile case as shown in Fig. 7(b).

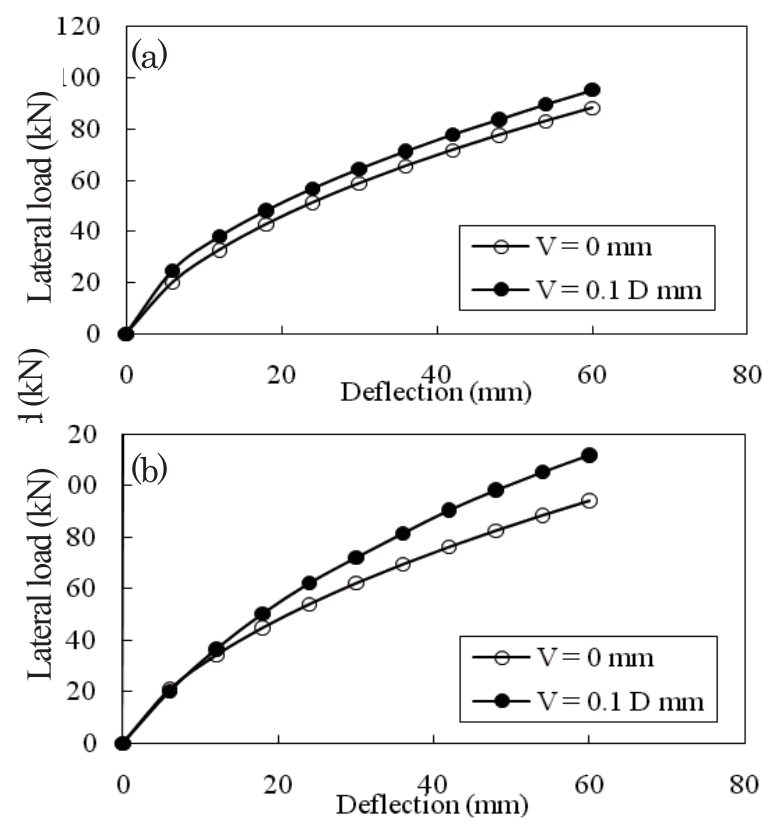

Fig. 7 Load-deflection curve of single piles: (a) free head pile, and (b) capped pile.

An attempt to identify the mechanism of the increase in the lateral resistance of the single pile subject to a vertical load was made by plotting the horizontal soil stress as well as the joint elements shear stresses along the upper part of the pile (the upper portion of the subsurface (5 to 10 pile diameter) is of predominant importance in pile-soil interaction due to lateral loading as suggested by Reese and Van Impe ${ }^{14)}$ ). These horizontal stresses induced before and after the application of the vertical load for both analyses with and without a pile cap as shown in Fig. 8(a). Figure 8(a) declares that the inclusion of vertical loads prior to lateral loads increases the horizontal stress of soil elements along the upper part of the pile depth $(4 \mathrm{~m})$ for both cases with and without a pile cap and the shape of the horizontal stress profile after these increases differ. The horizontal stress profile induced after the application of the vertical load on the free head case is affected only by the relative movement between the pile and the soil (soil-pile interaction), while the corresponding profile of the capped pile case is affected by the movements of both the pile and cap relative to the soil movement (soil-pile and soil-cap interactions). As shown in Fig. 8(a), the free head stress profile starts at the ground surface (where the stress levels are smaller and the soil response exhibits a higher degree of softening) and propagates downwards as the vertical stress transfer from the pile to the surrounding soil. On the contrary, the capped pile stress profile starts at the ground surface with a high stress value due to the confinement condition of the soil comes from the downward movement of the cap then the horizontal stress gradually decreases with the depth and approaches the stress profile of the free head case as the effect of soil-cap interaction vanishes. The difference between the confining pressure profile in capped pile case and the corresponding profile of the free head case may explain the difference in the percentages of lateral load capacity increase in the two cases.

The corresponding shear stress of joint elements for both cases free head and capped pile are plotted in Fig. 8(b). $\tau_{\mathrm{f}}$ calculated from Eq.(16) and corresponds to the
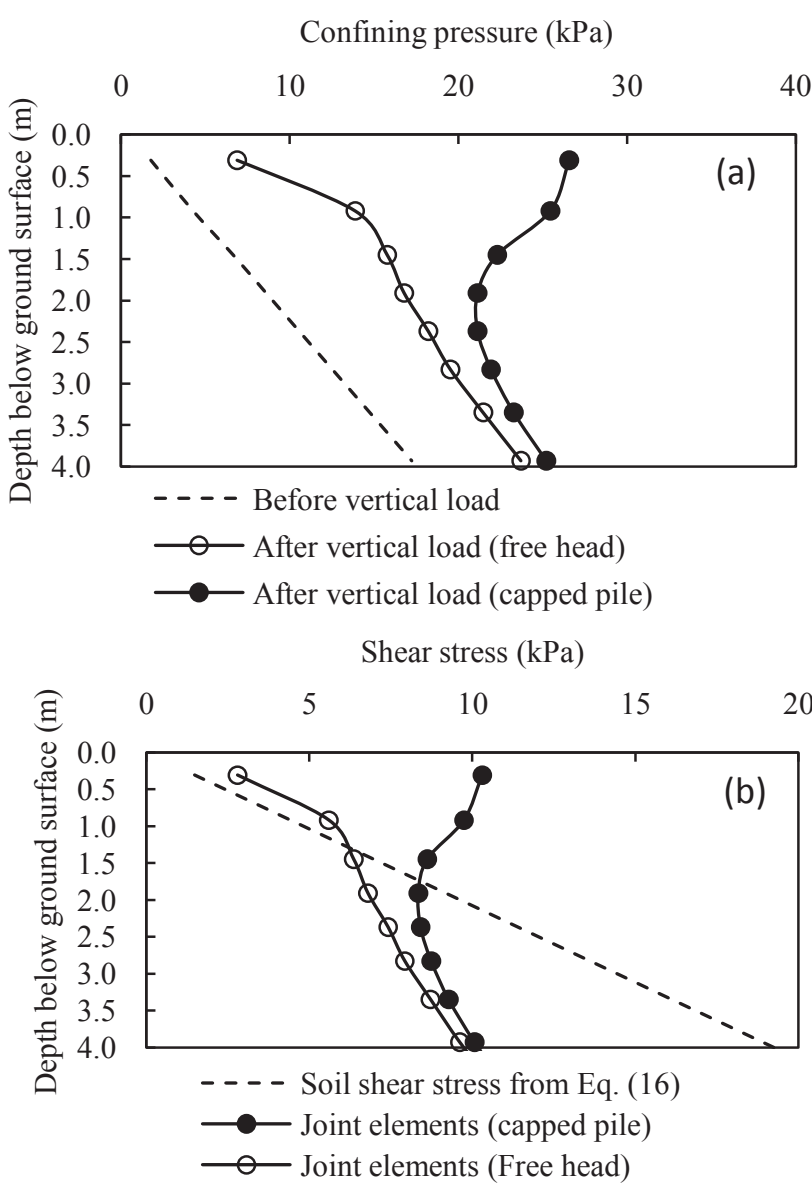

Fig. 8 Stress along the upper part of the pile: (a) horizontal soil stresses and (b) joint elements shear stresses 
soil shear stress at which sliding will initiate is also plotted for comparison. Figure 8(b) indicates that the behavior of joint element at shallow depths is highly affected by the inclusion of the cap and this effect decreases with depth. Similar to the horizontal soil stress, high shear stress value near the ground surface is formed in the case of capped pile and this high shear stress gradually decreases with depth and approaches the corresponding stress calculated in the free head pile case. As expected, not all joint elements slide. Only joint elements located at shallower depths will slide when the shear stress of these elements exceeds the shear stress limit $\left(\tau_{\mathrm{f}}\right)$ calculated using EQ. 16 and plotted in Fig 8(b). Figure $8(b)$ shows that the depth at which joint elements stop sliding differs in the two cases of free head and capped pile. This depth is about 1.25 and $1.75 \mathrm{~m}$ for free head and capped pile, respectively.

\section{Behavior of Pile Groups under the Combined Action of Vertical and Lateral Loads}

Loads were statically applied in the same manner as for the single pile. The same model parameters as those for the single pile were used. Figure 9 shows the load
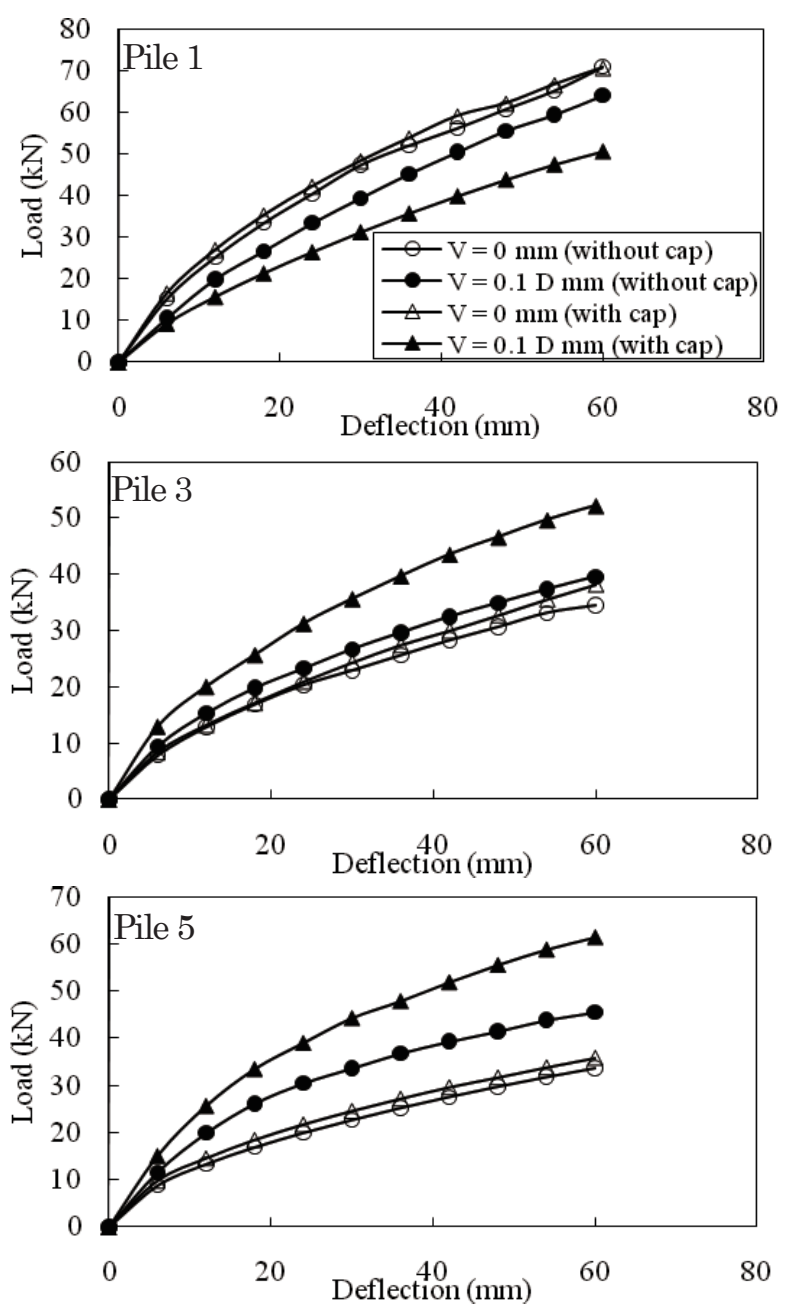

Fig. 9 Load-deflection curves for piles 1, 3, and 5.
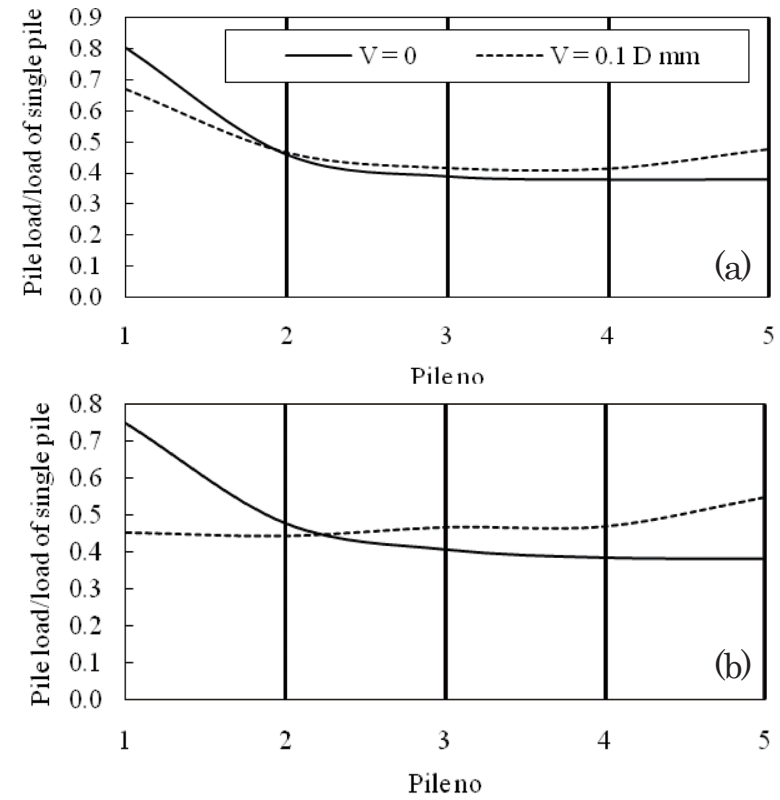

Fig. 10 Ratio of lateral load of each pile relative to the load of the corresponding single pile; deflection $=$ 60mm: (a) Free head, (b) Capped pile

versus pile head deflection of piles 1,3 , and 5 for the free head group compared to the corresponding curves for the capped group. These curves were computed with and without the presence of vertical loads. As shown in Fig. 9, the effect of vertical loads on the response of each pile in the free head pile group is not the same but is a function of the pile position. In the presence of vertical loads, the lateral load of the leading pile (pile 1) at all deflections is less than the corresponding load developed under pure lateral loads. The percentage reduction reached to a $10 \%$ at a $60 \mathrm{~mm}$ lateral deflection. For piles 3 and 5, the vertical loads increases the subsequent lateral loads at all deflections. The percentages of increase reached to 14 and $35 \%$ for piles 3 and 5 , respectively.

The lateral load-carrying capacity of each pile in the group (pure lateral load) was slightly increased in the presence of the cap. The effect of vertical loads on the lateral load carrying capacity of each pile in the capped group is similar to the free head case but with higher percentages of decrease or increase. The percentage of decrease of the lateral load carrying capacity of pile 1 at the maximum lateral deflection was $28 \%$ while the percentages of increase for piles 3 and 5 were 37 and $71 \%$, respectively. The inclusion of the pile cap amplify the effect of vertical loads on the subsequent lateral load response of piles.

In order to discuss the effect of vertical loads on the load distribution among piles in the group for both analyses with and without a pile cap, the ratios of the lateral load of each pile relative to the corresponding load of the single pile at the maximum deflection of 60 $\mathrm{mm}$ were plotted in Fig. 10. In particular, the free head pile group results are shown in Fig. 10(a) whereas those of the capped pile group are shown in Fig. 10(b). Figure 10 (a) and 10(b) show, for pure lateral load, that the leading pile carried the greatest load while the other 
piles including the trailing pile carried loads significantly less than the leading pile. As shown in Fig. 10(a), the presence of vertical loads on free head piles reduces the difference in pile loads but keep the shape of the load distribution curve (i.e. the leading pile carried the greatest load while the other piles carried loads less than the leading pile). Fig. 10(b) shows that the presence of vertical loads on capped group piles reverses the load distribution curve (i.e. the trailing pile carried the greatest load while other piles including the leading pile carried loads less than the trailing pile).

In order to discuss the mechanism of the change in the lateral response of each pile in the group due to vertical loads for free head piles and caped pile group, the horizontal soil stresses along the first four meters on piles. 1, 3, and 5 in the group are shown in Figs. 11(a), and 11(b) for the free head group and capped pile group, respectively. The stresses at the back of and in front of the piles were separately plotted. Figure 11(a) shows that, for pile 3 , the increases in horizontal soil stress along the pile depth due to the presence of vertical loads are the same for both sides of the pile. For pile 1, the increase in the horizontal stress at the back of the pile is larger than that in front of it due to the effect of the interaction of the next row of piles behind the leading pile (pile-pile interaction). For Pile 5, opposite trend with the same magnitude is observed. For middle pile (pile 3 ), there is no net lateral stress induced by vertical loads. This means pile 3 is little affected by the vertical load (see Fig. 10(a)). For the leading pile (pile 1), the net horizontal stress due to vertical loads acts in the same direction with the prospective lateral load, leading to a decrease in the pile resistance to the subsequent lateral load. For the trailing pile (pile 5), the net horizontal stress acts against the prospective lateral load, leading to an increase in the pile resistance to the subsequent lateral load.

On the other hand, the horizontal stress profiles induced in the capped pile group case are shown in Fig. 11(b). Figure 11(b) declares a highly uniform increase in the horizontal stresses of soil surrounding the piles after the application of vertical loads. With the application of lateral loads, the horizontal stresses stored in soil elements due to vertical loads in front of the leading pile may release while those stresses stored in the inner soil elements back to this pile will have little change due to the confinement of soil elements by piles and the cap and the difference between soil stresses (the net horizontal stress) due to vertical loads will act in the same direction with the prospective lateral load, leading to a decrease in the pile resistance to the subsequent lateral load. For the trailing pile, the net horizontal stress will act against the prospective lateral load, leading to an increase in the pile resistance to the subsequent lateral load.

\section{Conclusions}

The effect of vertical loads on the lateral response of a free head and capped pile group embedded in sandy soil has been studied in this paper through a series of 2D finite element analyses. The interaction between a pile and the surrounding soil in 3D type is idealized in the 2D analysis using soil-pile interaction spring with a hysteretic non-linear load displacement relationship. Of the findings of this study, the following conclusions can be drawn:

(1) The influence of vertical load is to increase the confining pressure in the sand deposit surrounding the pile, leading to an increase in the lateral pile resistance. A vertical load applied to a free head single pile with a vertical displacement of 0.1 pile diameter $(D=324 \mathrm{~mm})$ leads to an $8 \%$ increase in the lateral pile resistance at a $60 \mathrm{~mm}$ lateral deflection.

(2) The effect on individual piles in a free head pile group spaced at 3.92 pile diameters depends on the pile position. The vertical load leads to a $10 \%$ decrease in the lateral resistance of the leading pile (pile 1) and 14 and $35 \%$ increases in the lateral resistances of piles 3 and 5 , respectively.

(3) In addition to soil-pile interaction, soil-pile cap interaction play an important role in the increase the confining pressure surrounding a capped single pile leading to an amplification of the effect of the vertical load on the lateral response of the pile.

(4) The effect of vertical loads on the lateral load carrying capacity of individual pile in a capped pile group is similar to the free head case but with higher percentages of decrease or increase.

\section{References}

1) McNulty, J.F., Thrust loading on piles. Journal of the Soil Mechanics and Foundation Division (ASCE), 82(2), 1-25, 1956.

2) Sorochan, E.A. and Bykov, V.I., Performance of groups of cast-in place piles subject to horizontal loading. Journal of Soil Mechanics and Foundation Engineering, 13(3), 157-16, 1976.

3) Anagnostopoulos, C. and Georgiadis, M., Interaction of axial and lateral pile responses. Journal of Geotechnical Engineering (ASCE), 119(4), 793-798, 1993.

4) Zhang, L.M., McVay, M.C., Gardner, R., Han, Sanjoon, and Lai, Peter., Effects of dead loads on the lateral response of battered pile groups. Canadian Geotechnical Journal, 39(3), 561-575, 2002.

5) Karthigeyan S. and Ramakrishna VVGST., Interaction between vertical and lateral loads on the response of piles in soft clays, In: Proceeding of the 16th International Conference on Soil Mechanics and Geotechnical Engineering, Osaka, 1997-2000, 2005.

6) Karthigeyan S, Ramakrishna VVGST. and Rajagopal K., Influence of vertical load on the lateral response of piles in sand, Computers and Geotechnics, 33(2): 121-131, 2006. 


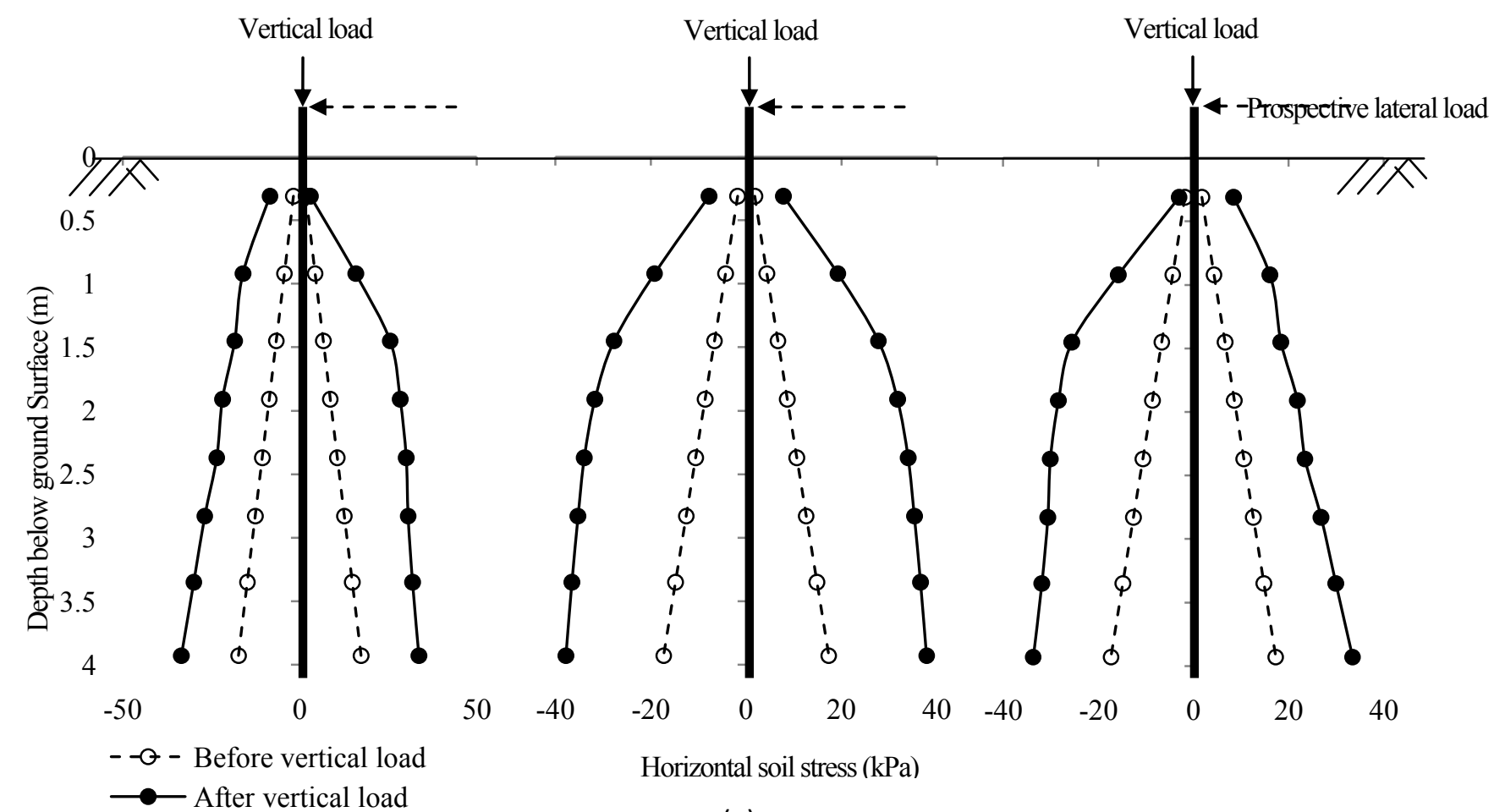

(a)

Pile (3)

Pile (5)

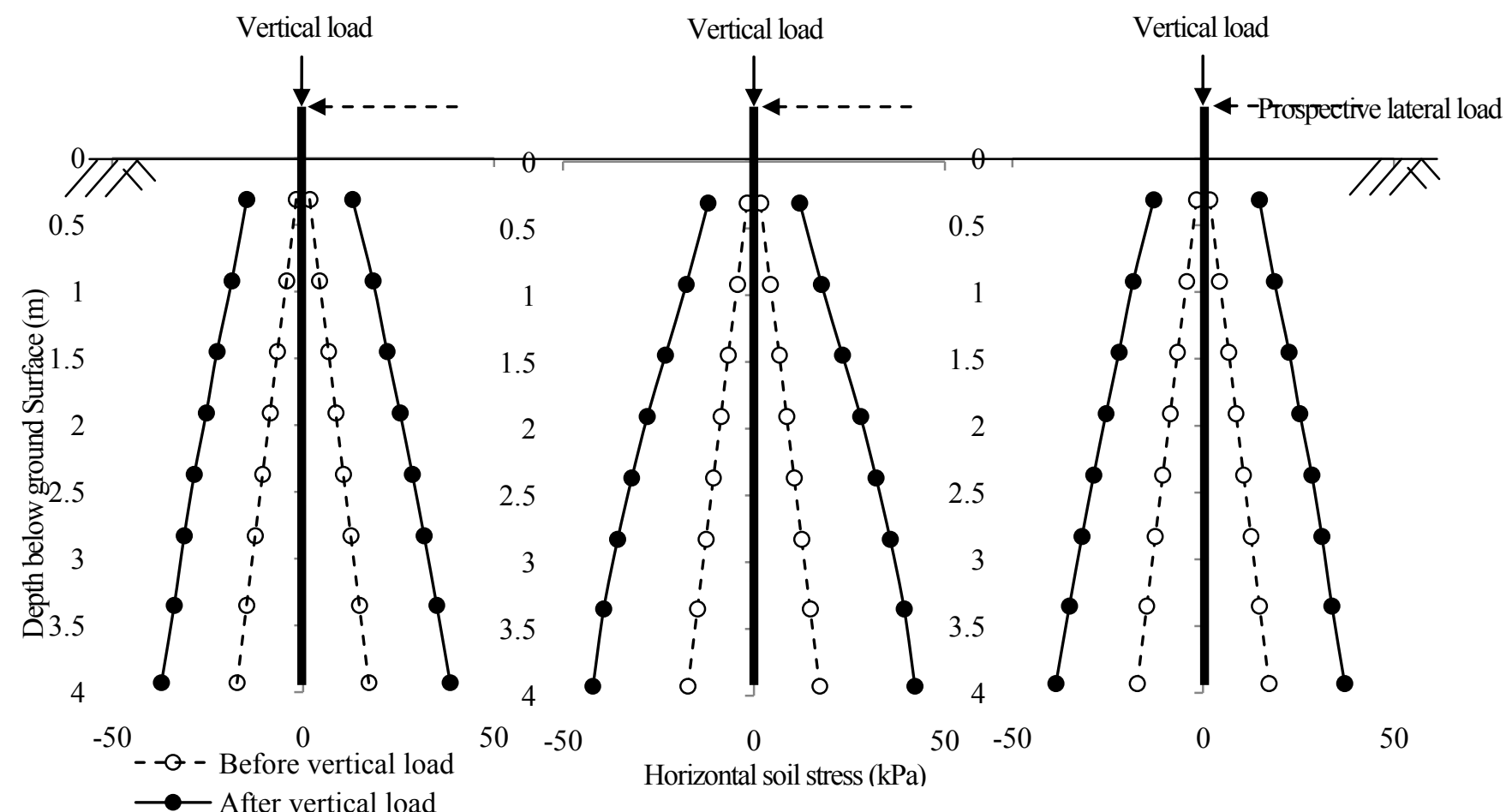

(b)

Figure 11. Horizontal soil stresses before and after the application of vertical loads along the upper part of the pile depth just at the back of and in front of piles 1, 3, and 5; free head pile group (a), capped pile group (b).

7) Karthigeyan S, Ramakrishna VVGST. and Rajagopal K., Numerical investigation of the effect of vertical load on the lateral response of piles, Journal of Geotechnical and Geoenvironmental Engineering (ASCE), 133(5): 512-521, 2007.

8) Iai S, Matsunaga Y. and Kameoka T., Strain space plasticity model for cyclic mobility, Soils and Foundations, 32(2): 1-15, 1992.

9) Snyder JL, Full-scale lateral-load tests of a $3 \times 5$ pile group in soft clays and silts, M.Sc. thesis, Brigham Young University, Provo, Utah, United States, 2004.

10) Tobita T, Iai S. and Rollins KM., Numerical analysis of 
full-scale lateral-load tests of a $3 \times 5$ pile group, In: Proceeding of the first European Conference on Earthquake Engineering and Seismology, Geneva, Switzerland, 2006.

11) Zhang L, McVay MC. and Lai P., Numerical analysis of laterally loaded $3 \times 3$ to $7 \times 3$ pile groups in sands, Journal of Geotechnical and Geoenvironmental Engineering (ASCE) 1999; 125(11): 936-946. 1999.

12) Iai S, Tobita $T$, Donahue M, Nakamichi $M$. and Kaneko $H$., Soil-pile interaction in horizontal plane: Seismic Performance and Simulation of Pile Foundations in Liquefied and Laterally Spreading Ground, Geotechnical
Special Publication (ASCE), 145: 38-49, 2006.

13) Ozutsumi O, Tamari Y, Oka Y, Ichii K, Iai S. and Umeki Y., Modeling of soil-pile interaction subjected to soil liquefaction in plane strain analysis, In: Proceeding of the 38th Japan National Conference on Geotechnical Engineering, Akita, Japan, 1899-1900, 2003.

14) Reese L.C, Van Impe W.F., Single piles and pile groups under lateral loading, A.A. Balkama, Rotterdam, Netherlands, 2001.

(Received: March 8, 2011) 